\title{
Editorial: Research Topic Crystal Nucleation and Growth in Magmatic Suspensions
}

\author{
Gianluca lezzi ${ }^{1 *}$, Julia E. Hammer ${ }^{2}$, Alan Whittington $^{3}$ and Daniel R. Neuville ${ }^{4}$ \\ ${ }^{1}$ University G. d'Annunzio Chieti-Pescara, Chieti, Italy, ${ }^{2}$ University of Hawaii, Honolulu, HI, United States, ${ }^{3}$ University of Texas at \\ San Antonio, San Antonio, TX, United States, ${ }^{4}$ Institut de physique du globe de Paris, CNRS, Université de Paris, \\ Géomatériaux, Paris, France
}

\section{Editorial on the Research Topic}

\section{Research Topic Crystal Nucleation and Growth in Magmatic Suspensions}

The differentiation, rheology and transport of magmas are strongly influenced by crystallization (nucleation and growth). Nucleation and crystal growth in a batch of magma evolve through time in response to changing environmental conditions, i.e., $T, P$, and $f \mathrm{O}_{2}$. Investigations on naturally formed igneous rocks, combined with experiments where these environmental conditions can be controlled, are necessary to decipher, reconstruct and model the solidification of magmas. New advances continue to be made in both analytical techniques and experimental methods, with crystallization under conditions of strong disequilibrium being a particularly active area of experimental research.

A host of difficulties confronts experimental studies of crystallization (nucleation, growth, and textural maturation), due to the high melting points, high degrees of chemical reactivity, and high redox sensitivities of natural (Fe-bearing) silicate liquids. These difficulties are compounded when the systems are investigated at elevated pressure or contain a high concentration of dissolved $\mathrm{H}_{2} \mathrm{O}$.

OPEN ACCESS

Edited and reviewed by: Carmen Sanchez-Valle, University of Münster, Germany

*Correspondence: Gianluca lezzi gianluca.iezzi@unich.it

Specialty section: This article was submitted to Earth and Planetary Materials,

a section of the journal

Frontiers in Earth Science

Received: 18 September 2020 Accepted: 30 September 2020

Published: 28 October 2020

Citation:

lezzi G, Hammer JE, Whittington A and Neuville DR (2020) Editorial: Research Topic Crystal Nucleation and Growth in Magmatic Suspensions. Front. Earth Sci. 8:607972. doi: 10.3389/feart.2020.607972
Frequently, solidification experiments are evaluated only post-quench; hence, the effect of a thermodynamic driving force (sensible cooling or decompression, if $\mathrm{H}_{2} \mathrm{O}$-saturated) and kinetic limitations on the evolution of nucleation, crystal growth, and textures is observed mainly ex situ. The in situ observation requires relaxation of one or more of these constraints, but unlocks the opportunity to study environmental controls on individual phase appearance (or suppression), maturation of crystal populations, and overall transformation kinetics.

This thematic issue contains five contributions to the study of magma crystallization. They share a reliance upon experimental data but differ in the application of in situ and ex situ methods, theoretical formulations, and the analysis of well-constrained natural volcanic samples.

With Crystallization Kinetics of Alkali Feldspar in Peralkaline Rhyolitic Melts: Implications for Pantelleria Volcano, Arzilli et al. perform 'classic' ex situ isobaric cooling experiments at controlled $\mathrm{fO}_{2}$ and various $\mathrm{H}_{2} \mathrm{O}$ concentrations. In this manner, they evaluate the kinetic crystallization of alkali feldspars in peralkaline rhyolitic magma over wide ranges in pressure and undercooling. This datarich contribution complements analogous studies on granite and granodiorite liquids by Fenn (1977) and Swanson (1977), quantifying the significant lag time between the imposition of a driving force for crystallization and the onset of crystallization.

In The Onset and Solidification Path of a Basaltic Melt by in situ Differential Scanning Calorimetry (DSC) and ex situ Investigations, Giuliani et al. combine DSC to pinpoint the onset of crystallization in natural basalt (at ambient conditions) with electron microscopy-based textural analysis of run products. A strength of the DSC technique is the opportunity to precisely resolve transformation kinetics. They report that an increase in cooling rate by three orders of magnitude suppresses the timing of the onset of crystallization by two orders of magnitude. They further estimate the effects of cooling rate on the nucleation of spinel, plagioclase, melilite, and 
clinopyroxene, estimating also their growth rates. DSC thermal signals unveil that crystallization proceeds mainly by "pulses," that can be correlated with kinks in the final crystal size distribution (CSD).

In their Disequilibrium Rheology and Crystallization Kinetics of Basalts and Implications for the Phlegrean Volcanic District, Kolzenburg et al., confront the study of crystallization kinetics with an equally novel and pragmatic in situ approach combined with ex situ crystal morphology observations. Via particle suspension rheology models, they determine the temperatures of crystallization onset and lockup (i.e., the "cutoff" when flow ceases to occur) for a basaltic magma. Their results are broadly consistent with the observation of Giuliani et al. about the onset of crystallization; also, they find a decrease of $\sim 100 \mathrm{~K}$ in cutoff temperature with a 10 -fold increase in cooling rate. Interestingly, although shearing has been shown to enhance crystal nucleation (Kouchi et al., 1986; Vona and Romano, 2013; Kolzenburg et al., 2018), the overall rate of solidification at $0.2 \mathrm{~K} / \mathrm{min}$ still lags behind equilibrium solidification (assessed via thermodynamic modeling) until nominal undercooling of $\sim 40 \mathrm{~K}$.

In Theoretical Models of Decompression-Induced Plagioclase Nucleation and Growth in Hydrated Silica-Rich Melts, Mollard et al. access fundamental theoretical constructs for the basis of their treatment of crystal nucleation and growth. First, they backsolve the classical nucleation theory (Volmer and Weber, 1926) to obtain the crystal-liquid surface energy by the plagioclase formation during experimental decompression of $\mathrm{H}_{2} \mathrm{O}$-saturated haplotonalite. Modifications to the classical nucleation theory, particularly regarding nucleus roughness and shape, are considered. Analysis of compositional gradients in the vicinity of plagioclase crystals underpins their determination of the $\mathrm{CaO}$-in-liquid diffusion coefficient. Using the new $\mathrm{D}_{\mathrm{CaO}}$, they model the growth of plagioclase crystals as a diffusion-controlled process at moderate undercooling.

In her review paper, Crystal Size Distribution (CSD) Analysis of Volcanic Samples: Advances and Challenges, Cashman summarizes the early application of textural analysis as a means of understanding the crystallization processes in different contexts (i.e., industry, experimental petrology labs, and in natural environments). CSD theory owes its

\section{REFERENCES}

Fenn, P. M. (1977). The nucleation and growth of alkali feldspars from hydrous melts. Canad. Mineral. 15, 135-161.

Kolzenburg, S., Giodano, D., Hess, K. U., and Dingwell, D. B. (2018). Shear ratedependent disequilibrium rheology and dynamics of basalt solidification. Geophys. Res. Lett. 45, 6466-6475. doi:10.1029/2018GL077799

Kouchi, A., Tsuchiyama, A., and Sunagawa, I. (1986). Effect of stirring on crystallization kinetics of basalt: texture and element partitioning. Contribut. Mineral. Petrol. 93, 429-438. doi:10.1007/BF00371713

Swanson, S. E. (1977). Relation of nucleation and crystal-growth rate to the development of granitic textures. Am. Mineral. 62, 966-978.

Volmer, M., and Weber, A. (1926). Germ-formation in oversaturated figures. Zeitschrift für Physicalische Chemie Stochiometrie und Verwandtschaftslehre 119, 227-301. doi:10.1515/zpch-1926-11927 interpretive power to the special case of steady-state conditions, allowing to predict the interplay between nucleation rate, growth rate, and characteristic crystal size. When the steady-state criterion can be reasonably applied, there is potential to retrieve from a CSD the duration over which crystallization has occurred. Additional complexities and insights arising from laboratory simulations of crystallization modifying CSDs are examined in detail. These difficulties include the interdependence of nucleation and growth rate; coarsening and size-dependent growth; and a rekindled recognition of superliquidus thermal history as an impediment to subliquidus crystal nucleation. A method is presented for allocating crystal volumes appropriately to phenocryst and groundmass populations, leveraging textural characterization with compositional analysis, and demonstrating a way forward for CSD analysis.

The latest theoretical models of magmatic crystallization build upon those proposed at the beginning of the last century to describe simple chemical systems. While the earlier studies of simple systems (composed of two to four thermodynamic components) pertain to chemical systems where the parent liquid solidifies into one or two solid phases (crystals and glass) with close or identical compositions, magmas are inherently more complex. The multicomponent parent liquid is not thermodynamically ideal and the solidifying phases are usually also non-ideal solutions that differ in composition from the liquid. Many more investigations and experiments will be required to achieve a wholly general model of solidification of magmas. This special issue looks back to the advances made during the last 50-60 years and bridges forward to foreshadow new theoretical, analytical, and experimental techniques that are poised to reveal physico-chemical processes producing the igneous rocks of the Earth and terrestrial planets.

\section{AUTHOR CONTRIBUTIONS}

JH wrote the first draft of the editorial, GI added some other parts and review it. AW and DN reviewed the draft. All the topic editors agree on this final version.

Vona, A., and Romano, C. (2013). The effects of undercooling and deformation rates on the crystallization kinetics of Stromboli and Etna basalts. Contribut. Mineral. Petrol. 166, 491-509. doi:10.1007/s00410013-0887-0

Conflict of Interest: The authors declare that the research was conducted in the absence of any commercial or financial relationships that could be construed as a potential conflict of interest.

Copyright (c) 2020 Iezzi, Hammer, Whittington and Neuville. This is an open-access article distributed under the terms of the Creative Commons Attribution License (CC $B Y)$. The use, distribution or reproduction in other forums is permitted, provided the original author(s) and the copyright owner(s) are credited and that the original publication in this journal is cited, in accordance with accepted academic practice. No use, distribution or reproduction is permitted which does not comply with these terms. 